\title{
Effect of Binder Content on the Non-linear Creep Properties of Polymer Bonded Explosives
}

\author{
Cong-Mei LIN ${ }^{\mathrm{a}^{*}}$, Li-Ping PAN, Jian-Hu ZHANG, Guan-Song HE, \\ Jia-Hui LIU and Shi-Jun LIU \\ Institute of Chemical Materials, China Academy of Engineering Physics, Mianyang, Sichuan \\ 621900, P. R. China. \\ alincmei2009@caep.cn, *Isj99@sohu.com
}

Keywords: polymer bonded explosive, TATB, non-linear creep properties, binder content.

\begin{abstract}
The non-linear creep behavior of 1,3,5-triamino-2,4,6-trinitrobenzene (TATB)-based polymer bonded explosives (PBXs) with different binder content has been measured under different stresses and temperatures. Reduced creep strain and steady-state creep strain rate and prolonged creep failure time were observed with decreasing binder content, suggesting enhanced creep resistance performance. Subsequently, the effects of applied stress and temperature on the creep resistance were also explored. The proposed model, based on Maxwell and two Kelvin units, was proved to describe the three-point bending creep behaviors for TATB-based PBXs tested. In addition, the relations of the binder content and the mechanical response were investigated by compressive tests and dynamic mechanical analysis.
\end{abstract}

\section{Introduction}

As a kind of particle highly-filled polymer composite, 1,3,5-triamino-2,4,6-trinitrobenzene (TATB)-based PBX is considered to be one of the most important systems which are potential for practical applications in military filed.[1-4 ]Several PBX materials have been formulated with TATB as a explosive crystal in the last decades, such as LX-17 (92.5\% 1,3,5-triamino-2,4,6-trinitrobenzene TATB and 7.5\% fluoropolymer kel-F800 by weight) and PBX-9502 (95\% TATB and 5\% kel-F800 by weight).[5-7]

The deformation and damage behavior of PBX subjected to various loads and prone to deformation and damage during storage, transportation, and usage have received worldwide concern and increasing research interest.[8-11] High fidelity measurements of time-dependent creep strain in the plastic-bonded explosives LX-17-1 and PBX-9502 have been carried out and it has been pointed out that the creep and recovery behavior of PBX was dependent on the type of explosive, the type of binder, the stress level and test temperature.[12]

The ratio of the explosive component to the polymer binder varies from one material to the next, but, typically, the explosive component comprises $80-95 \%$ of the mass of the composite [13]. Less attention is paid to the effects of polymer binder on the creep resistance of TATB-based PBX. In this work, TATB-based PBXs filled with different concentrations of polymer binder were designed and fabricated by water suspension methods. An attempt has been made to correlate the observed creep properties of TATB-based PBX with loading stress, temperature and polymer binder concentration.

\section{Experimental Section}

\section{Materials}

1,3,5-triamino-2,4,6-trinitrobenzene (TATB) with 97\% purity was obtained from Institute of Chemical Materials, CAEP, China. A copolymer of chlorotrifluoroethylene and vinylidene fluoride 
provided by Zhonghao Chenguang Chemical Industry Co., Ltd. China was used as a polymer binder.

\section{Sample Preparation}

TATB-based PBXs with 5\%, 10\%, and 20\% fluoropolymers were labelled as PBX-1, PBX-2, and PBX-3, respectively. The molding powders for TATB-based PBXs were prepared by water suspension methods.The explosive pellet was pressed in a mould and used for mechanical and creep tests.

\section{Measurements}

The compressive tests of the TATB-based PBXs specimens were performed using an Instron5582 machine (Canton, MA, USA) at a room temperature of $23{ }^{\circ} \mathrm{C}$. The crosshead speed was set at 10 $\mathrm{mm} / \mathrm{min}$. At least three specimens of each PBX were tested, and the load-displacement curves were recorded.

Dynamic mechanical analysis (DMA) was conducted with a DMA 242C apparatus (Netzsch, Germany) in three-point bending mode at a frequency of $1 \mathrm{~Hz}$. The heating rate was set for $1{ }^{\circ} \mathrm{C} / \mathrm{min}$.

The three-point bending creep analysis of the samples was performed using a dynamic mechanical analyzer (DMA 242C, Netzsch, Germany). The specimens for three-point bending creep experiments were $30 \mathrm{~mm}$ long, $10 \mathrm{~mm}$ wide and $1 \sim 2 \mathrm{~mm}$ thick. In every case, the creep load was applied for a period of $5400 \mathrm{~s}$ at a set temperature.

\section{Results and Discussion}

\section{Static Mechanical Analysis}

The load-displacement curves as a function of the test time during compressive tests of three different testing samples for TATB-based PBXs were recorded and the representative mechanical characteristics are shown in Table 1 . No new absorbance difference appeared in the TATB-based PBXs, indicating that binder content would not affect the compressive strength of PBXs. As expected, a decrease of the compressive modulus of TATB-based PBXs is achieved by the increase of binder content.

Table 1 Mechanical characteristic of the TATB-based PBXs with deferent binder contents

\begin{tabular}{cccc}
\hline sample & $\begin{array}{c}\text { compressive strength } \\
\text { /MPa }\end{array}$ & $\begin{array}{c}\text { compressive modulus } \\
\text { /GPa }\end{array}$ & $\begin{array}{c}\text { compressive elongation at } \\
\text { break /\% }\end{array}$ \\
\hline PBX-1 & 25.81 & 7.61 & 1.96 \\
PBX-2 & 26.56 & 6.29 & 3.37 \\
PBX-3 & 26.09 & 5.54 & 3.28 \\
\hline
\end{tabular}

\section{Dynamic Mechanical Properties}

Dynamic mechanical analysis (DMA) is used characterize the viscoelastic properties of the materials. Figure 1 shows the dynamic mechanical spectrum of TATB-based PBXs. All composites exhibit a decreased storage modulus with increasing temperature. In addition, the storage modulus decreased regularly with the increasing binder content. The trend in the variation of storage modulus with the binder content was found to be similar to the behavior of compressive modulus. An inflexion or a peak value, corresponding to the $T_{g}$ of corresponding polymer binders, exists in the loss factor curves for the TATB-based PBXs. 

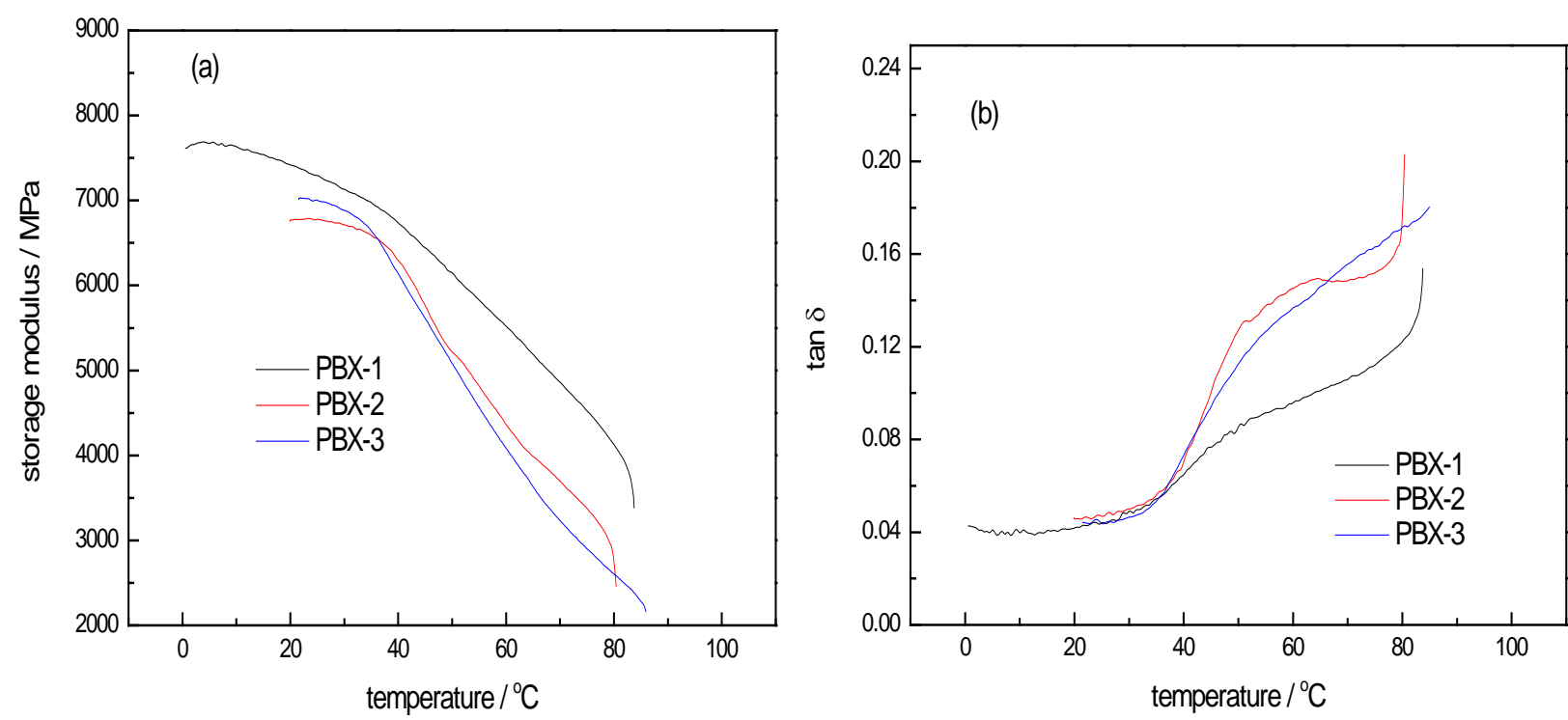

Fig. 1. Dynamic mechanical (a) storage modulus and (b) tan $\delta$ as a function of temperature for TATB-based PBXs.

\section{Three-point Bending Creep Tests}

\section{Creep Strain Curves under Different Stresses}

Typical creep curves under different stresses for TATB-based PBXs were presented in Figure 2. The creep performance parameters, including the steady-state creep strain rate, maximal creep strain, and creep failure time of TATB-based PBXs, are listed in Table 2. It can be clearly seen that with the increase in stress the steady-state creep strain rate and maximal creep strain increases and creep failure time shortened. Furthermore, it is visibly apparent that with the decrease in polymer binder content the magnitude of creep strain undergoes a large reduction. Compared to PBX-1 with 5\% polymer binder, the creep rupture time for the PBX-2 and PBX-3 with $10 \%$ and $20 \%$ of binder content at $60{ }^{\circ} \mathrm{C} / 7 \mathrm{MPa}$ decreased by $9.0 \%$ and $84.5 \%$, respectively, which indicates reduced creep resistance.

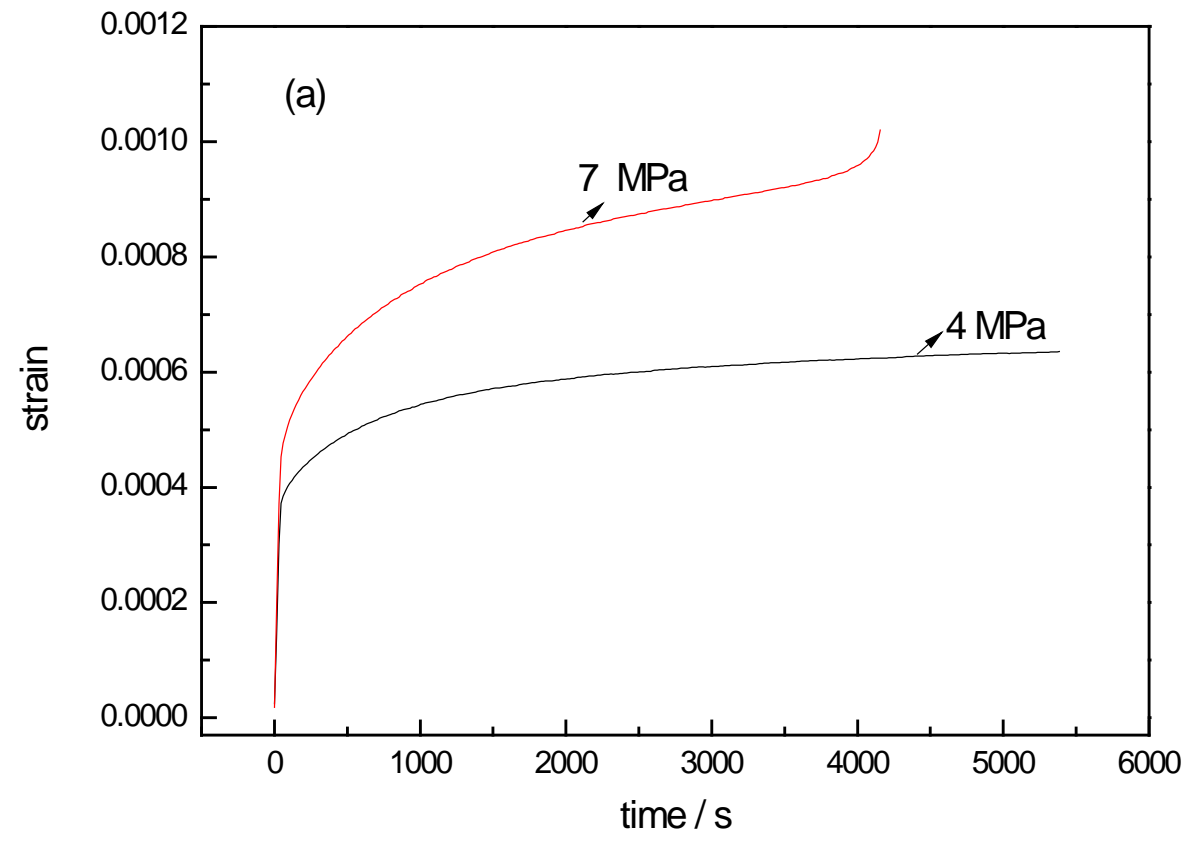



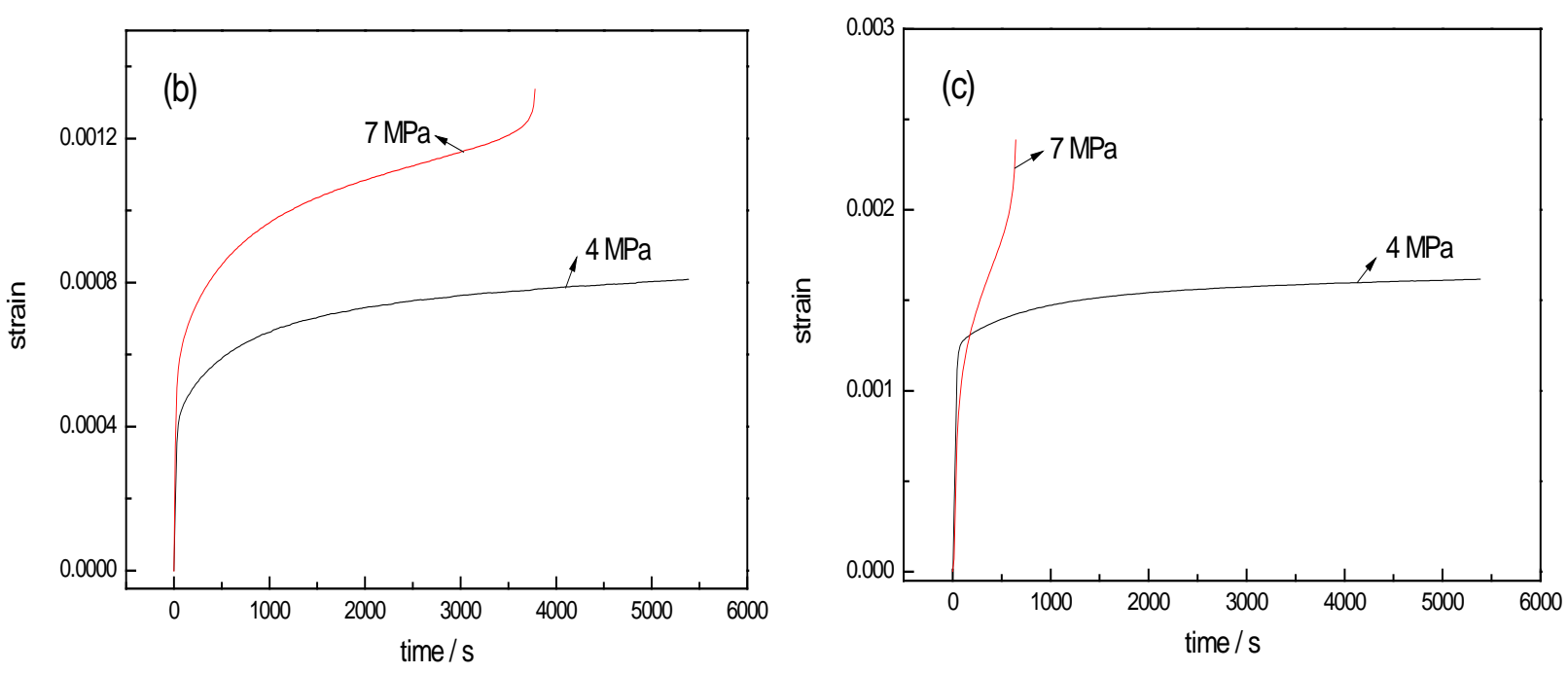

Fig. 2 Time-dependent creep strain of TATB-based PBXs under different stresses at $60{ }^{\circ} \mathrm{C}$ : (a) PBX-1, (b) PBX-2, (c) PBX-3.

Table 2 The creep performance parameters of TATB-based PBXs under different conditions

\begin{tabular}{ccccc}
\hline sample & $\begin{array}{c}\text { experimental } \\
\text { conditions }\end{array}$ & $\begin{array}{c}\text { steady-state creep } \\
\text { strain rate } / \mathrm{s}^{-1}\end{array}$ & $\begin{array}{c}\text { maximal creep } \\
\text { strain }\end{array}$ & $\begin{array}{c}\text { creep rupture } \\
\text { time } / \mathrm{s}\end{array}$ \\
\hline \multirow{2}{*}{$\mathrm{PBX}-1$} & $60^{\circ} \mathrm{C} / 4 \mathrm{MPa}$ & $1.397 \times 10^{-8}$ & $6.356 \times 10^{-4}$ & $>5400$ \\
& $60^{\circ} \mathrm{C} / 7 \mathrm{MPa}$ & $5.152 \times 10^{-8}$ & $1.020 \times 10^{-3}$ & 4155 \\
$\mathrm{PBX}-2$ & $60^{\circ} \mathrm{C} / 4 \mathrm{MPa}$ & $2.298 \times 10^{-8}$ & $8.088 \times 10^{-4}$ & $>5400$ \\
& $60^{\circ} \mathrm{C} / 7 \mathrm{MPa}$ & $7.880 \times 10^{-8}$ & $1.340 \times 10^{-3}$ & 3780 \\
$\mathrm{PBX}-3$ & $60^{\circ} \mathrm{C} / 4 \mathrm{MPa}$ & $2.192 \times 10^{-8}$ & $1.620 \times 10^{-3}$ & $>5400$ \\
& $60^{\circ} \mathrm{C} / 7 \mathrm{MPa}$ & $1.536 \times 10^{-6}$ & $2.390 \times 10^{-3}$ & 645 \\
\hline
\end{tabular}

\section{Creep Strain Curves at Different Temperatures}
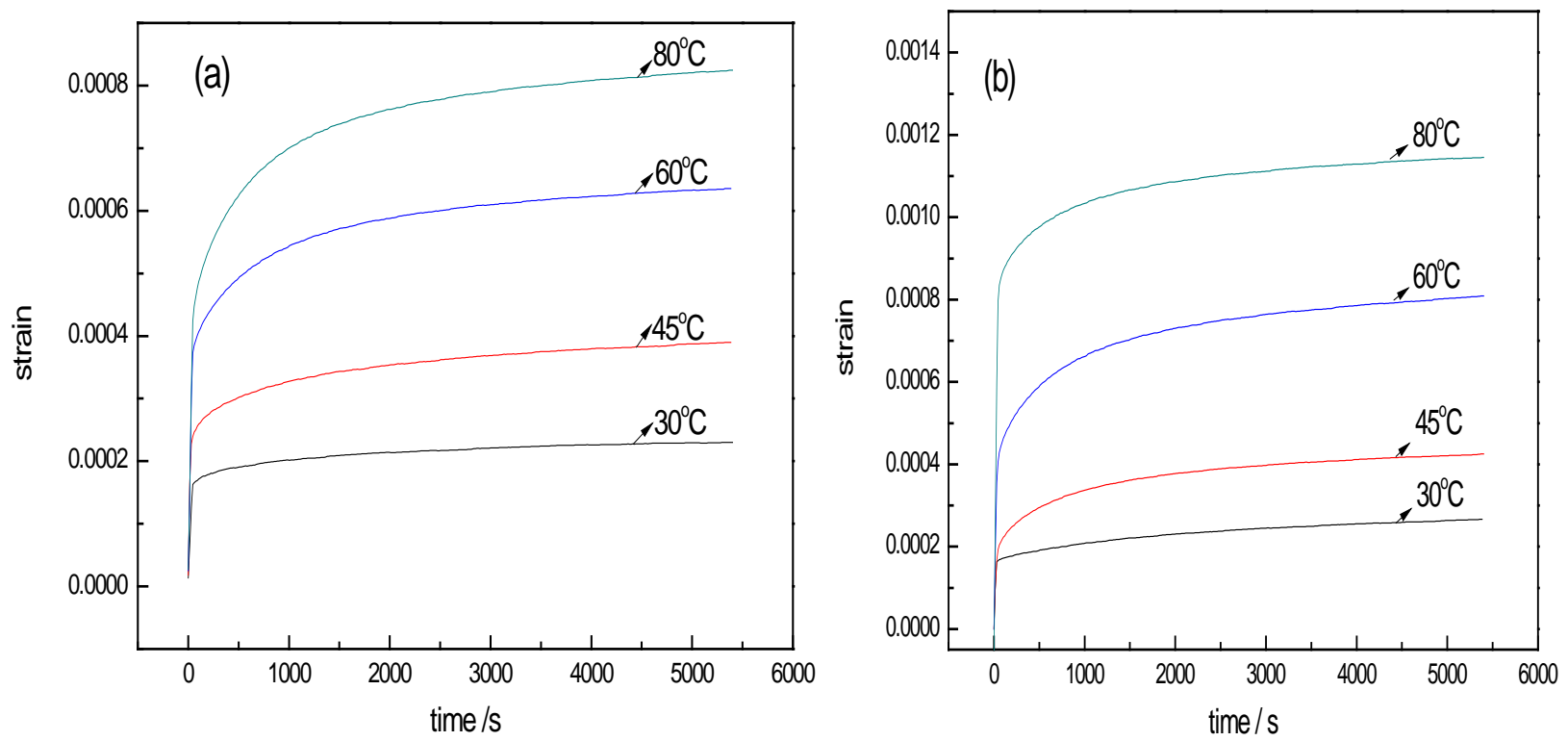


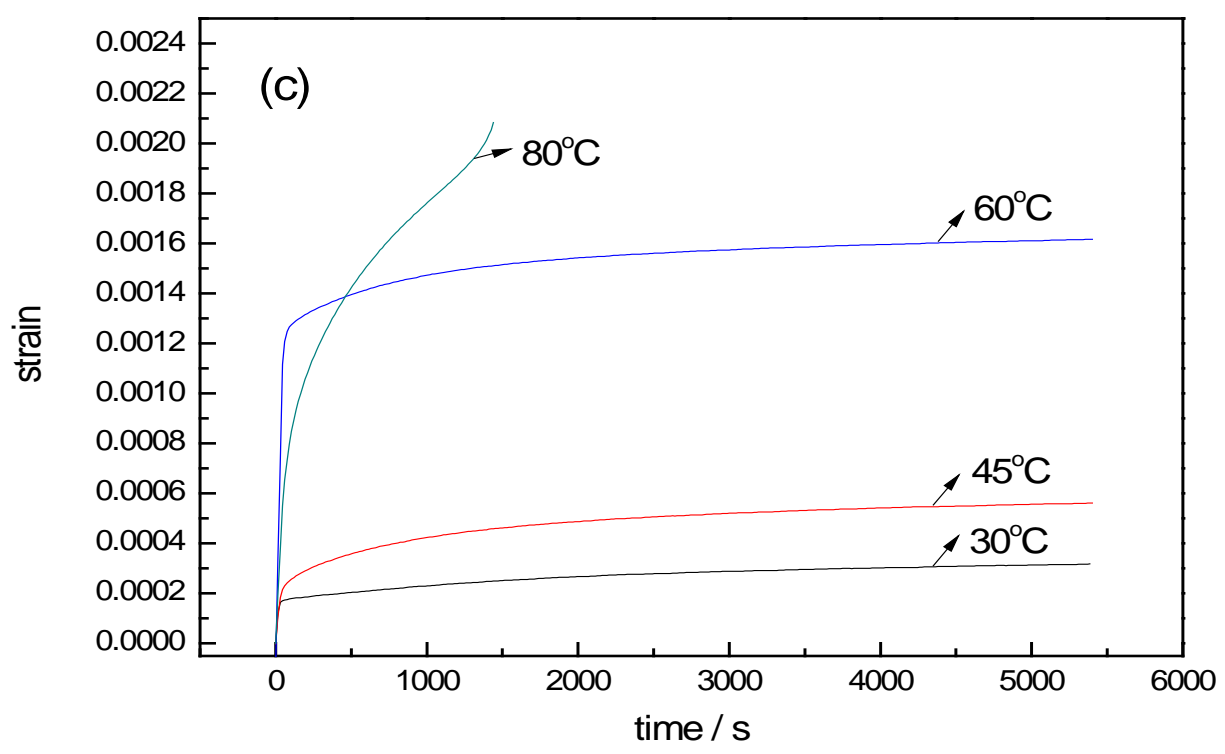

Fig. 3 Time-dependent creep strain of TATB-based PBXs at different temperatures under 4 MPa: (a) PBX-1, (b) PBX-2, (c) PBX-3.

Figure 3 shows creep strain-time curves for the examined TATB-based PBXs at different temperatures. It can be found that the creep strain of PBXs rises with increasing temperatures.This behavior can be attributed to a higher macromolecular mobility and higher deformation during creep process. Furthermore, a prominent increase of the creep strain is achieved by the increase of polymer binder content at all temperatures.

\section{Modeling of Creep Curves}

In the following, a six-element mechanical model is presented that is proposed to predict the creep behavior of the material tested. The six-element mechanical model consists of a consecutively connected Maxwell and two Kelvin units, as illustrated in Figure 4. According to the proposed model, there is a total strain ( $\varepsilon$ ) of polymer composite material PBX which could be determined by the strains resulting from the Maxwell spring $\left(\varepsilon_{1}\right)$, Maxwell dashpot $\left(\varepsilon_{4}\right)$, and two Kelvin units $\left(\varepsilon_{2}\right.$ and $\varepsilon_{3}$ ). It can be described by the following equation:

$$
\varepsilon(t)=\varepsilon_{1}+\varepsilon_{2}+\varepsilon_{3}+\varepsilon_{4}=\frac{\sigma_{0}}{E_{1}}+\frac{\sigma_{0}}{E_{2}}\left(1-e^{-t / \tau_{2}}\right)+\frac{\sigma_{0}}{E_{3}}\left(1-e^{-t / \tau_{3}}\right)+\frac{\sigma_{0}}{\eta_{4}} t
$$

where $\varepsilon(\mathrm{t})$ denotes a function of creep strain $\varepsilon$ with creep time $t, \sigma_{0}$ is the initial stress, $\mathrm{E}_{1}$ is the elastic modulus of instantaneous elastic deformation, $E_{2}$ and $E_{3}$ are the elastic modulus of high elastic deformation, $\tau_{2}$ and $\tau_{3}$ are the relaxation time, $\eta_{4}$ is the bulk viscosity, respectively.

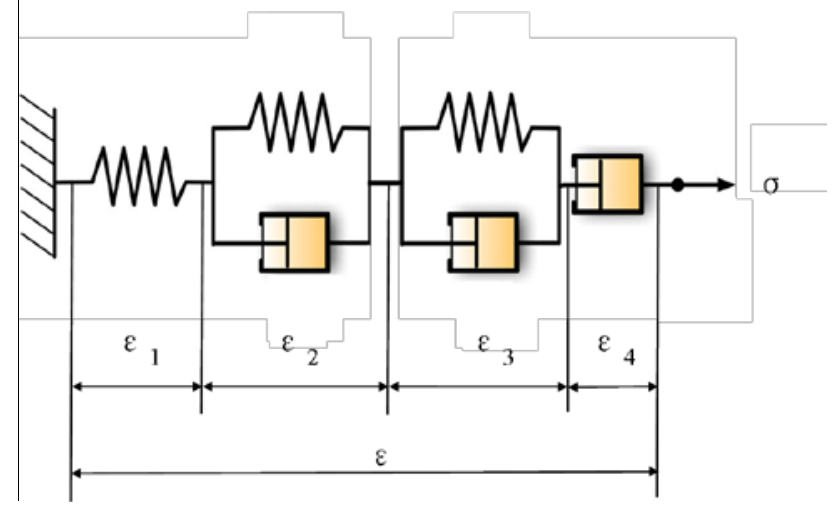

Fig. 4 Schematic representation of the six-element mechanical model.

The quality of fitting in the creep strain curves under representative load levels (4 MPa) is shown 
in Figure 5. The parameters including the elastic modulus $E_{1}, E_{2}, E_{3}$, the relaxation time $\tau_{2}, \tau_{3}$, as well as the bulk viscosity $\eta_{4}$ have been evaluated and are listed in Table 3. It is proved that the creep strain curve of Figure 5 can be predicted in a very satisfactory way with the high square values of correlation coefficient $\left(\mathrm{R}^{2}\right)$. The parameters, including the elastic modulus $\mathrm{E}_{2}$, $\mathrm{E}_{3}$, as well as the bulk viscosity $\eta_{4}$ were observed to be dependent upon the temperature and the binder content.
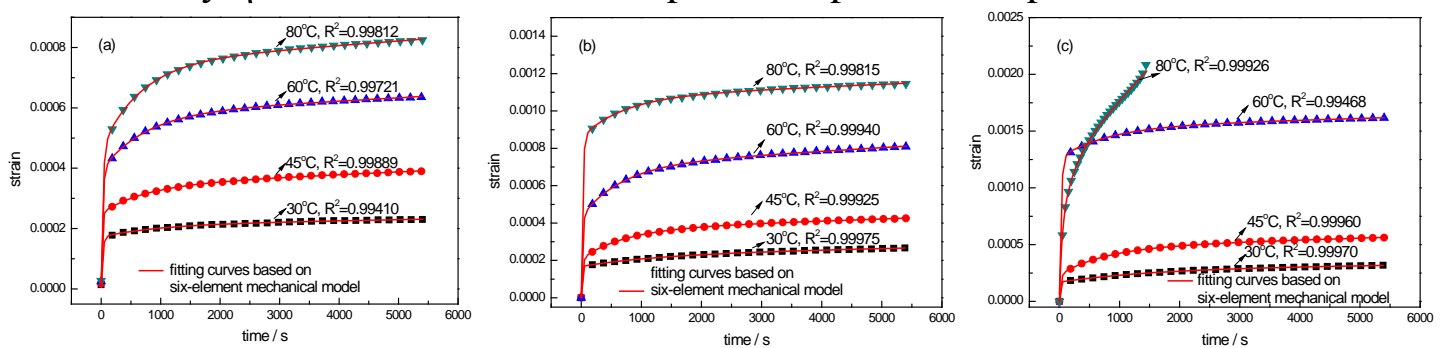

Fig. 5 Modeling results of creep behaviors of TATB-based PBXs at different temperatures under 4 MPa: (a) PBX-1, (b) PBX-2, (c) PBX-3.

Table 3 The fitting parameters of six-element model under different conditions

\begin{tabular}{cccccccc}
\hline \multirow{2}{*}{ sample } & test condition & $\begin{array}{c}\mathrm{E}_{1} \\
\mathrm{MPa}\end{array}$ & $\begin{array}{c}\mathrm{E}_{2} \\
/ \mathrm{MPa}\end{array}$ & $\begin{array}{c}\tau_{2} \\
/ \mathrm{s}\end{array}$ & $\begin{array}{c}\mathrm{E}_{3} \\
/ \mathrm{MPa}\end{array}$ & $\begin{array}{c}\tau_{3} \\
/ \mathrm{s}\end{array}$ & $\begin{array}{c}\eta_{4} \\
/ \mathrm{MPa} \cdot \mathrm{s}\end{array}$ \\
\hline \multirow{3}{*}{$\mathrm{PBX}-1$} & $30^{\circ} \mathrm{C} / 4 \mathrm{MPa}$ & $5.760 \times 10^{5}$ & $9.999 \times 10^{4}$ & 974.50 & $2.419 \times 10^{4}$ & 25.08 & $1.150 \times 10^{9}$ \\
& $45^{\circ} \mathrm{C} / 4 \mathrm{MPa}$ & $2.720 \times 10^{5}$ & $4.359 \times 10^{4}$ & 745.24 & $1.723 \times 10^{4}$ & 15.52 & $4.394 \times 10^{8}$ \\
& $60^{\circ} \mathrm{C} / 4 \mathrm{MPa}$ & $4.431 \times 10^{5}$ & $2.128 \times 10^{4}$ & 734.98 & $1.043 \times 10^{4}$ & 24.82 & $3.779 \times 10^{8}$ \\
& $80^{\circ} \mathrm{C} / 4 \mathrm{MPa}$ & $5.341 \times 10^{5}$ & $1.403 \times 10^{4}$ & 665.43 & $8.773 \times 10^{3}$ & 28.96 & $2.727 \times 10^{8}$ \\
& $30^{\circ} \mathrm{C} / 4 \mathrm{MPa}$ & $2.396 \times 10^{6}$ & $6.314 \times 10^{4}$ & 1317.76 & $2.415 \times 10^{4}$ & 9.47 & $5.873 \times 10^{8}$ \\
$\mathrm{PBX}-2$ & $45^{\circ} \mathrm{C} / 4 \mathrm{MPa}$ & $1.602 \times 10^{6}$ & $2.514 \times 10^{4}$ & 728.32 & $1.942 \times 10^{4}$ & 22.37 & $3.548 \times 10^{8}$ \\
& $60^{\circ} \mathrm{C} / 4 \mathrm{MPa}$ & $5.258 \times 10^{6}$ & $1.461 \times 10^{4}$ & 675.99 & $9.250 \times 10^{3}$ & 20.27 & $2.061 \times 10^{8}$ \\
& $80^{\circ} \mathrm{C} / 4 \mathrm{MPa}$ & $6.890 \times 10^{5}$ & $1.874 \times 10^{4}$ & 710.47 & $4.689 \times 10^{3}$ & 22.94 & $2.829 \times 10^{8}$ \\
& $30^{\circ} \mathrm{C} / 4 \mathrm{MPa}$ & $2.021 \times 10^{7}$ & $3.382 \times 10^{4}$ & 1591.89 & $2.359 \times 10^{4}$ & 9.686 & $6.565 \times 10^{8}$ \\
& $45^{\circ} \mathrm{C} / 4 \mathrm{MPa}$ & $9.710 \times 10^{4}$ & $1.667 \times 10^{4}$ & 808.32 & $1.717 \times 10^{4}$ & 24.77 & $2.469 \times 10^{8}$ \\
& $60^{\circ} \mathrm{C} / 4 \mathrm{MPa}$ & $6.023 \times 10^{4}$ & $1.469 \times 10^{4}$ & 829.43 & $3.337 \times 10^{4}$ & 27.60 & $2.678 \times 10^{8}$ \\
& $80^{\circ} \mathrm{C} / 4 \mathrm{MPa}$ & $1.298 \times 10^{6}$ & $6.816 \times 10^{3}$ & 217.19 & $6.674 \times 10^{3}$ & 39.98 & $6.879 \times 10^{6}$ \\
\hline
\end{tabular}

\section{Conclusions}

In this paper, TATB-based PBXs with different polymer binder contents were was examined in three-point bending creep experiments. A nonlinear viscoelastic model was developed to describe the creep response. The following conclusions can be drawn:

(1) The creep strain for TATB-based PBXs were observed to be dependent upon the applied stress, temperature and the binder content. The lowest creep strain and longest creep lifetime were exhibited on the composite with a lowest value of $5 \%$ polymer binder.

(2) The three-point bending creep strain curves for TATB-based PBXs have been modeled using a six-element mechanical model. The results shows good agreement between the creep experimental data and predictions of the model.

\section{Acknowledgement}

The authors are grateful to the Science and Technology Fund of CAEP (2015B0101011) and National Natural Science Foundation of China (11372290 and 11502245) for financial support. 


\section{References}

[1] C. Zhang, Y. Ma, and D. Jiang, J. Mol. Model., 2012, 18, 4831-4841.

[2] R. H. Gee, S. Roszak, K. Balasubramanian, and L. E. Fried, J. Chem. Phys., 2004, 120, 7059-7066.

[3] Z. J. Yang, J. S. Li, B. Huang, S. J. Liu, Z. Huang, and F. D. Nie, Propell. Explos. Pyrot., 2014, 39, 51-58.

[4] J. T. Mang and R. P. Hjelm, Propell. Explos. Pyrot., 2013, 38, 831-840.

[5] C. Souers, P. Lewis, M. Hoffman, and B. Cunningham, Propell. Explos. Pyrot., 2011, 36, 335-340.

[6] R. L. Gustavsen, R. J. Gehr, S. M. Bucholtz, R. R. Alcon, and B. D. Bartram, J. Appl. Phys., 2012, 112, 074909.

[7] W. Small IV, E. A. Glascoe, and G. E. Overturf, Thermochim. Acta, 2012, 545, 90-95.

[8] C. Lin, S. Liu, X. Tu, Z. Huang, Y. Li, L. Pan, and J. Zhang, Propell. Explos. Pyrot., DOI: 10.1002/prep.201400203.

[9] C. Lin, S. Liu, Z. Huang, G. He, F. Gong, Y. Liu, and J. Liu, RSC Adv., 2015, 5, 30592-30601.

[10]C. Lin, J. Liu, F. Gong, G. Zeng, Z. Huang, L. Pan, J. Zhang, and S. Liu, RSC Adv., 2015, 5, 21376-21383.

[11]C. Lin, J. Liu, G. He, L. Chen, Z. Huang, F. Gong, Y. Liu, and S. Liu, RSC Adv., 2015, 5, 35811-35820.

[12]F. J. Gagliardi and B. J. Cunningham, Creep testing plasticbonded explosives in uni-axial compression, LLNL-CONF-402307, 2008.

[13]P. W. Cooper and S. R. Kurowski, Introduction to the Technology of Explosives, New York: Wiley-VCH, p.21-23, 1996. 